\title{
Twelve-month outcomes of ranibizumab for diabetic macular edema in routine clinical practice in Mexico
}

\section{Resultados del tratamiento a doce meses con ranibizumab para el edema macular diabético en la práctica clínica de rutina en México}

Luis P. Orozco-Gómez', Leonor Hernández-Salazar ${ }^{1}$, Vanesa Flores-Peredo², Alma L. Ortega-Villalobos ${ }^{3}$, Sergio Aranda-Serna ${ }^{1}$, Luis Gerardo-Ferreyra ${ }^{1}$, Elisa Pérez-González¹, Julio Pérez-Monjaraz ${ }^{1}$ and Alejandra Sabina Ruiz-Franco ${ }^{4 *}$

${ }^{1}$ Centro Médico Nacional 20 de Noviembre, Mexico City, Mexico; ${ }^{2} \mathrm{Hospital}$ Lic. Adolfo López Mateos, Mexico City, Mexico; ${ }^{3} \mathrm{Hospital} 1{ }^{\circ}$ de Octubre, Mexico City, Mexico; ${ }^{4}$ Hospital Regional Gral, Ignacio Zaragoza. ISSSTE, Mexico City, Mexico

\begin{abstract}
Purpose: The purpose of this study was to evaluate visual acuity (VA) and central retinal thickness (CRT) outcomes in patients treated with ranibizumab for diabetic macular edema (DME) in a clinical setting in Mexico. Methods: A prospective, open-label, single-arm study was performed on 48 eyes of 34 patients with center-involving DME at four high-specialty ISSSTE hospitals in Mexico. Patients initially received a loading dose of three injections of ranibizumab followed by monthly monitoring based on VA and CRT to determine retreatment need. VA, CRT, early treatment diabetic retinopathy (DR) study (ETDRS) $D R$ severity scale (DRSS) score, and number of injections were recorded at baseline and monthly for 12 months. Results: The mean VA, mean CRT, and mean DRSS score at baseline were $19( \pm 14)$ ETDRS letters, $362( \pm 98) \mu m$ and $50.59( \pm 7.9)$. The mean VA change at 12 months was $+8.6( \pm 4.3)$ letters $(p<0.001)$ from baseline. The proportion of eyes that gained $\geq 10$ letters was $38.58 \%(n=19)$ and $37.50 \%(n=18)$ gained < 10 letters; $4.16 \%(n=2)$ had no change; and $18.75 \%(n=9)$ lost $<10$ letters. At month 12, mean CRT change was $-85.34( \pm 32.1) \mu \mathrm{m}(p<0.001)$ and the DRSS score was $45.79( \pm 7.9)$ $(p<0.001)$. Patients received a mean of 6.7 ( \pm 2.2$)$ injections over 12 months. Conclusion: Patients showed visual and anatomical improvement after receiving ranibizumab in a clinical setting in Mexico.
\end{abstract}

Key words: Diabetic macular edema. Ranibizumab. Anti-vascular endothelial growth factor. Diabetic retinopathy. Intravitreal injection. Mexico.

\section{Resumen}

Objetivo: Evaluar los resultados de agudeza visual (AV) y grosor central de la retina (GCR) en pacientes con edema macular diabético (EMD) tratados con ranibizumab en la práctica clínica de rutina en México. Métodos: Se realizó un estudio prospectivo, abierto y de un solo grupo en 48 ojos de 34 pacientes con EMD con involucro central, en cuatro hospitales de alta especialidad del ISSSTE. Los pacientes iniciaron con una dosis de carga de tres inyecciones de ranibizumab $0.5 \mathrm{mg}$,

Correspondence:

${ }^{*}$ Alejandra Sabina Ruiz-Franco

Calz. Gral. Ignacio Zaragoza, 1711

Col. Ejército Constitucionalista Date of reception: 04-05-2019

C.P. 09220, Iztapalapa, Mexico City, Mexico Date of acceptance: 20-06-2019

E-mail: asruiz222@gmail.com

DOI: 10.24875/RMOE.M19000080

Available online: 01-09-2019 Rev Mex Oftalmol (Eng). 2019;93(5):17-24

www.rmo.com.mx 2604-1731/@ 2019 Sociedad Mexicana de Oftalmología. Published by Permanyer México SA de CV. This is an Open Access article under the CC BY-NC-ND license (http://creativecommons.org/licenses/by-nc-nd/4.0/). 
seguido de monitoreo mensual con base en la AV y el GCR, para determinar la necesidad de retratamiento. La AV, el GCR, el puntaje en la Escala de severidad de la retinopatía diabética (DRSS) del ETDRS y el número de inyecciones se capturaron desde la basal y de manera mensual hasta los 12 meses. Resultados: La AV promedio, el GCR promedio y el puntaje promedio de la DRSS en la basal fueron $19( \pm 14)$ letras ETDRS, $362( \pm 98) \mu \mathrm{m}$ y $50.59( \pm 7.9)$, respectivamente. El cambio promedio en AV a los 12 meses fue de +8.6 ( \pm 4.3$)$ letras $(p<0.001)$ respecto a la basal. El $39.58 \%$ de los ojos $(n=19)$ ganó $\geq 10$ letras y el $37.50 \%(n=18)$ ganó < 10 letras. El $4.16 \%(n=2)$ se mantuvo estable y el $18.75 \%(n=9)$ perdió < 10 letras. A 12 meses, el cambio promedio en el GCR fue de $-85.34( \pm 32.1) \mu \mathrm{m}(p<0.001)$. El puntaje promedio de la DRSS fue de 45.79 ( \pm 7.9$)$ en el mes 12 ( $p<0.001)$. Una media de $6.7( \pm 2.2)$ inyecciones fue aplicada durante 12 meses. Conclusión: Los pacientes mostraron mejoría visual y anatómica después de recibir ranibizumab en la práctica clínica en México.

Palabras clave: Edema macular diabético. Ranibizumab. Anti-vascular endothelial growth factor. Retinopatía diabética. Inyección intravitrea. México.

\section{Introduction}

Type 2 diabetes mellitus (DM2) affects approximately 415 million people in the world ${ }^{1}$ with an estimated prevalence of $9.2 \%$ in the Mexican adult population². Diabetic retinopathy (DR) is a microvascular complication of this disease and is present in $70 \%$ of patients with DM2 in Mexico ${ }^{3}$. Diabetic macular edema (DME) occurs at any stage of DR and its incidence increases with the duration of $\mathrm{DM} 2^{4}$. Along with DR, DME constitutes one of the leading causes of visual impairment and legal blindness among working-age adults ${ }^{4}$, representing a burden for the Mexican health-care system today.

Laser photocoagulation was the standard treatment for DME before the advent of anti-vascular endothelial growth factor (VEGF) therapy, which significantly improves functional and anatomical outcomes compared to laser treatment ${ }^{5}$. Several multicentric studies have evaluated the efficacy and safety of intravitreal ranibizumab for DME. The Phase II study RESOLVE demonstrated the safety and efficacy of monthly ranibizumab in DME over 12 months, resulting in the best-corrected visual acuity (BCVA) gains of +10.3 early treatment $D R$ study (ETDRS) letters from baseline ${ }^{6}$. The RESTORE extension study showed that individualized treatment with ranibizumab effectively improves and maintains functional and anatomical outcomes for over 36 months with a progressively declining number of injections per year? ${ }^{7}$. Furthermore, the RETAIN study showed the non-inferiority of ranibizumab treat-and-extend regimen versus ranibizumab pro re nata (PRN) over 12 and 24 months ${ }^{8}$.

Randomized clinical trials, nevertheless, have restrictive inclusion and exclusion criteria, which might limit their ability to fully represent broader populations. Real-world data are, therefore, necessary to assess treatment effectiveness in the clinical setting as well as report the economic impact of both diseases and interventions in specific countries and health-care institutions $^{9}$. In this regard, several studies have confirmed the effectiveness of ranibizumab in routine clinical practice $e^{10-12}$, and to the best of our knowledge, there are no studies evaluating clinical outcomes of ranibizumab in Mexican patients with DME.

\section{Purpose}

The aim of this study was to report visual and anatomical outcomes of ranibizumab in patients with DME in a real-world setting in Mexico.

\section{Methods \\ Study design}

The present study is an interventional, prospective, single-arm, open-label, multicentric study conducted in four high-specialty ISSSTE hospitals in Mexico City. Patients received intravitreal ranibizumab injections in one or both eyes between January 2015 and December 2015. The study was approved by the Research Committee of ISSSTE National Medical Center "20 de Noviembre" and adhered to the tenets of the Declaration of Helsinki. All participants provided written informed consent for the study participation. The study was registered with the number 507-2015.

\section{Participants}

Enrolled subjects aged $\geq 18$ years old, males and females, with visual impairment due to DME. Patients had a baseline BCVA between 20/40 and 20/800 Snellen equivalent, baseline central retinal thickness (CRT) 
$\geq 250 \mu \mathrm{m}$ on cirrus HD - optical coherence tomography (OCT), retinal fluorangiographic studies, and glycated hemoglobin $(\mathrm{HbA} 1 \mathrm{c}) \leq 14 \%(130 \mathrm{mmol} / \mathrm{mol})$.

Patients with the presence or suspected intraocular infection were excluded from the study, as well as those with myocardial ischemia or cerebrovascular events 6 months before entering the study. Patients with vitreomacular traction, macular ischemia, ocular surgery within 3 months before study start, vitreous hemorrhage, and patients requiring concomitant therapy with steroids were also excluded from the study.

Patients were withdrawn from the study if they required intraocular surgery, refused to keep on participating or were lost to follow-up.

\section{Intervention}

Patients were treated according to ISSSTE institutional guidelines for diagnosis and treatment of $\mathrm{DME}^{13}$. A loading dose of 3 monthly injections of ranibizumab $0.5 \mathrm{mg}$ (Lucentis ${ }^{\circledR}$, Novartis) was given to all patients followed by monthly monitoring including BCVA and OCT. Treatment was put on hold in case of stable vision for at least 2 consecutive months and resolution of edema. Retreatment criteria included loss of $\geq 5$ ETDRS letters, increase of CRT $\geq 10 \%$ from prior visit, and/or persistent edema on OCT images, with subsequent injections until BCVA of 20/20 was achieved and/or remained stable for 2 months, and/or CRT was $<250 \mu \mathrm{m}$.

\section{Outcome measures}

Primary clinical endpoint was mean change in BCVA (number of letters obtained by VA ETDRS chart) from baseline to 12 months. Secondary endpoints included mean change in CRT obtained by Cirrus HD-OCT (Carl Zeiss Meditec) from baseline to 12 months, mean time to achieve CRT $<250 \mu \mathrm{m}$, change in the mean ETDRS DR severity scale (DRSS) score, number of intravitreal injections received over 12 months, and factors affecting BCVA and CRT outcomes.

\section{Statistical analysis}

We performed sample size calculations to obtain the desired sample size needed for the study. A sample size calculation was performed, to obtain a hypothesis contrast of mean difference for dependent groups a mean difference in simple of 6.2 letters and a standard deviation of 6.1, according to the results of the RETAIN study in its PRN treatment arm, with a basal mean of
63.4 letters, \pm 11.15 using an alpha value of 0.05 and a power of 0.8 , resulting in 41 eyes.

Student's t-tests were performed to compare the means of continue and quantitative variables and McNemar's $\chi^{2}$ tests for the analysis of dichotomous variables. A Kaplan-Meier survival curve was used to measure the fraction of subjects showing a CRT < $250 \mu \mathrm{m}$ over 12 months. Binary logistic regression analyses were conducted to determine the relationship between independent variables and categorized outcomes for BCVA and CRT, namely, BCVA gain > 10 and $<10$ letters, loss or no loss of letters, and CRT $>250$ or $<250 \mu \mathrm{m}$ at month 12. $p=0.005$ was considered statistically significant in all analyses. SPSS software version $21\left(\mathrm{IBM}^{\circledR}\right)$ was used.

\section{Results}

\section{Baseline characteristics}

A total of 48 eyes of 34 patients were included in the study. Nineteen were male (56\%), the mean age of all patients was 61.6 years with a mean duration of DM2 of 16.8 years (range 1-33) and mean $\mathrm{HbA1c}$ value of $7.9 \%$ (range $5.5-13.1 \%)(63 \mathrm{mmol} / \mathrm{mol}, 37-120)$. At baseline, mean BCVA was 19 letters (range 5-47) and mean CRT was $362 \mu \mathrm{m}$ (range 215-839). Withdrawal of consent was the most common reasons for discontinuation follow-up, eight patients were eliminated.

Table 1 summarizes baseline clinical characteristics.

\section{Best-corrected VA}

Mean BCVA after 12 months was 27.62 ETDRS letters (range 3-55). Mean change from baseline to month 12 was $+8.62( \pm 4.3)$ letters (Fig. 1), showing a statistically significant difference from baseline $(p<0.001)$. The mean maximum value of BCVA (28 letters) was observed after the third ranibizumab injection and maintained to month 12. Eyes were classified into three groups according to BCVA outcomes at month 12 (Table 2). Visual improvement was experienced by $77.08 \%$ of eyes ( $n=37$ ); $39.58 \%$ of the total $(n=19)$ gained $\geq 10$ letters, while $4.16 \%(n=2)$ had no change and $18.75 \%(n=9)$ lost between 1 and 3 letters.

\section{CRT}

At month 12, the mean CRT was $273.32 \mu \mathrm{m}$, which represents a significant mean reduction of 85.34 $( \pm 32.1) \mu \mathrm{m}(23.79 \%)$ from baseline $(p<0.001)$. Figure 2 


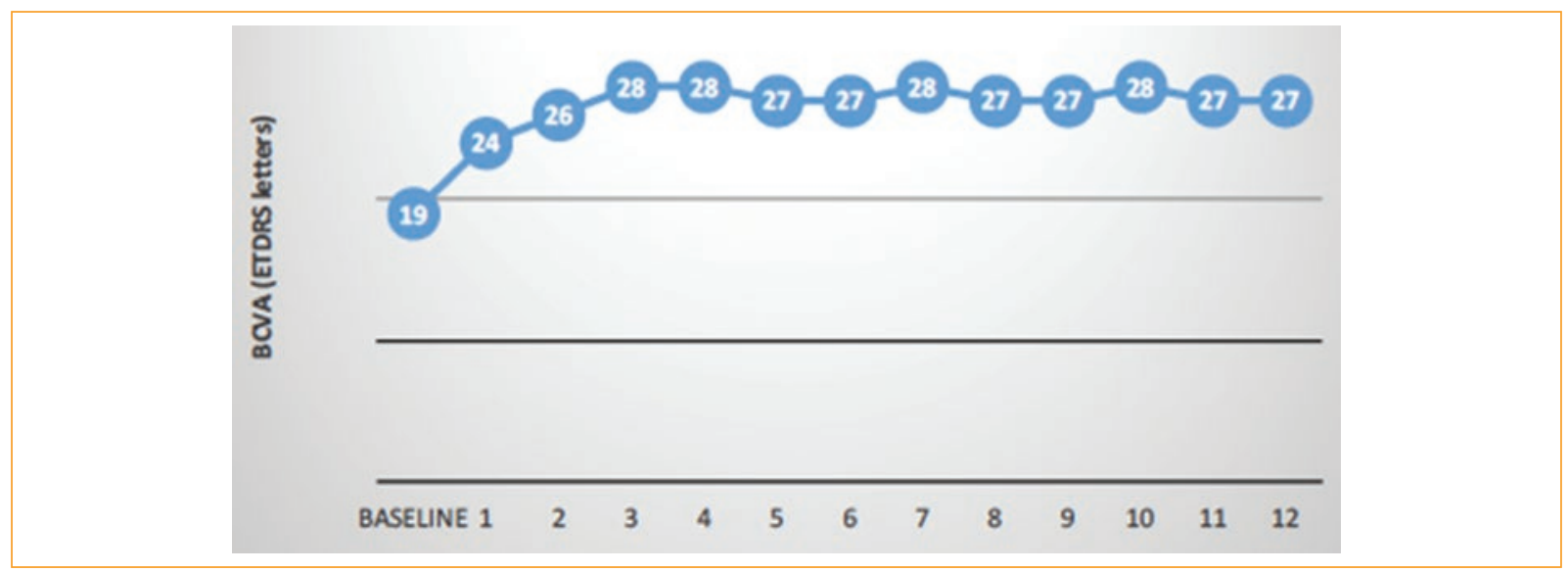

Figure 1. Mean change in visual acuity from baseline to month 12.

Table 1. Baseline characteristics

\begin{tabular}{|c|c|c|}
\hline Characteristic & Value & Range \\
\hline Age, years $\pm S D$ & $61.65 \pm 7.9$ & $35-75$ \\
\hline \multicolumn{3}{|l|}{ Gender number } \\
\hline Male (\%) & $19(56)$ & \\
\hline Female $(\%)$ & $15(44)$ & \\
\hline Duration of DM2, years & $16.8 \pm 5.4$ & $1-33$ \\
\hline BCVA, ETDRS letters & $19 \pm 14$ & $5-47$ \\
\hline CRT, $\mu \mathrm{m}$ & $362 \pm 98$ & $215-839$ \\
\hline $\mathrm{HbA} 1 \mathrm{c}, \%(\mathrm{mmol} / \mathrm{mol})$ & $7.9 \pm 2.2(63)$ & $5.5-13.1(37-120)$ \\
\hline \multicolumn{3}{|l|}{ Eyes treated } \\
\hline Left eye (\%) & $27(56.2)$ & \\
\hline Right eye (\%) & $21(43.8)$ & \\
\hline Total of eyes & 48 & \\
\hline
\end{tabular}

Table 2. BCVA final classification

\begin{tabular}{l|c|c|}
\hline BCVA outcomes & $\begin{array}{c}\text { Number of eyes (range of } \\
\text { BCVA change) }\end{array}$ & $\begin{array}{c}\% \text { of total } \\
\text { eyes }\end{array}$ \\
\hline $\begin{array}{c}\text { Visual improvement } \\
\geq 10 \text { ETDRS letters }\end{array}$ & $37(+4 \mathrm{a}+40)$ & 77.08 \\
\hline 10 ETDRS letters & 19 & 39.58 \\
\hline Stable BCVA & 2 (0) & 37.50 \\
\hline $\begin{array}{l}\text { Vision loss } \\
\text { +: gain letters, -: lost letters, ETDRS: early treatment diabetic retinopathy study, } \\
\text { BCVA: best-corrected visual acuity. }\end{array}$
\end{tabular}

depicts mean CRT obtained every month from baseline to month 12.

The Kaplan-Meier survival curve (Fig. 3) demonstrated that $41.3 \%$ of eyes achieved a CRT $<250 \mu \mathrm{m}$ after the first intravitreal injection, 62.5\% after the second dose, and $67 \%$ at the $3^{\text {rd }}$ month, with a median of 3.37 months (confidence interval [Cl] 95\%, 2.42-4.38).

\section{Severity of DR}

Table 3 shows the patient distribution according to ETDRS DRSS at baseline, and 6 and 12 months. At month 12, a numerical reduction in the percentage of patients with non-proliferative severe DR was observed compared to baseline (from $20.83 \%$ to $10.41 \%$ ). Similarly, the percentage of proliferative DR cases reduced from $18.74 \%$ to $8.33 \%$.

Mean ETDRS DRSS score showed a significant change from $50.59( \pm 7.9)$ to $45.79( \pm 7.9)$ at month $12(p<0.001)$.

\section{Number of injections}

Patients received a mean of 6.7 ranibizumab injections per treated eye over 12 months. This number includes the 3 monthly injections of the loading phase and subsequent PRN retreatment doses. The total number of injections received during the study was 323 .

\section{Factors affecting visual and anatomical outcomes}

The binary logistic regression analysis showed that none of the predictor variables had a statistically significant impact on BCVA outcome at 12 months (Table 4). 


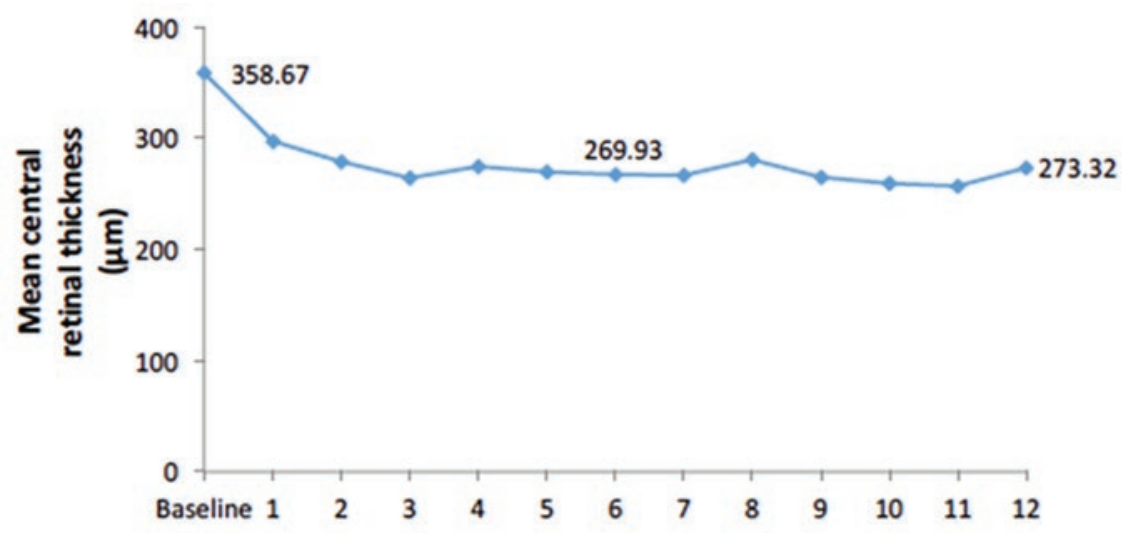

Figure 2. Mean change in central retinal thickness from baseline to month 12 .

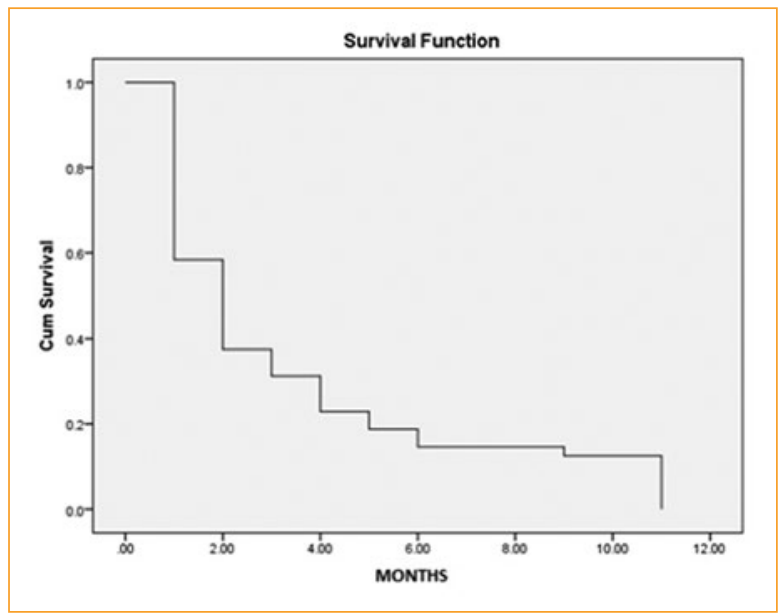

Figure 3. Kaplan-Meier survival curve for fraction of eyes with central retinal thickness $<250 \mu \mathrm{m}$. About $67 \%$ of patients showed a CRT $<250 \mu \mathrm{m}$ at month 3 , which highlights the importance of administering a loading dose to ensure positive treatment outcomes.

Furthermore, the binary logistic regression analysis did not find a significant association between any variable and visual improvement of $>10$ letters or $<10$ letters at the end of the study (Table 5).

Finally, the binary logistic regression analysis for final CRT found that baseline CRT was the only factor significantly associated to persistent macular thickness at month 12 ( $p=0.032, \mathrm{Cl}$ 95\%) (Table 6).

\section{Discussion}

High prevalence of DM2 is a public health concern in Mexico. DME is a leading cause of vision loss in patients living with DM ${ }^{4}$. ISSSTE is one of the largest health-care institutions in Mexico and provides ranibizumab treatment to patients with clinically significant DME. This study is the first to describe 12-month outcomes of anti-VEGF therapy in 48 eyes of 34 patients with DME in Mexico.

Baseline characteristics in the present study, including duration of DM2 and HbA1c levels, were similar to those reported in other clinical studies. Our results showed a mean gain of 8.62 letters in BCVA from baseline to month 12, which is similar to that reported in the RETAIN study (+ 7.4 ETDRS letters at month 12 with ranibizumab $0.5 \mathrm{mg} P R N)^{8}$. Maximum visual improvement was observed after the third injection and maintained at month 12. Similarly, an observational study evaluating the use of ranibizumab in routine clinical care in Sweden reported significant visual gains in 50\% of patients with DME after 4 months of treatment, which maintained through 12 months $^{12}$.

Regarding anatomical outcomes, we observed a mean reduction of $23.79 \%$ in CRT from baseline to month 12 in the present study. This is similar to the $27.09 \%$ reduction shown in the ranibizumab PRN regimen arm of the RETAIN study despite baseline CRT not being numerically similar in both studies $(362 \mu \mathrm{m}$ vs. $432 \mu \mathrm{m}$, respectively) ${ }^{8}$. The Kaplan-Meier survival curve found that after receiving 3 monthly injections, $67 \%$ of the eyes had a CRT $<250 \mu \mathrm{m}$. This confirms the importance of the loading dose in achieving treatment goal. With $41.3 \%$ of the patients showing a favorable reduction in CRT in the $1^{\text {st }}$ month, it might be reasonable to perform preliminary assessment of treatment response after receiving the first ranibizumab injection. 
Rev Mex Oftalmol (Eng). 2019;93

Table 3. ETDRS diabetic retinopathy severity scale at baseline, and 6 and 12 months

\begin{tabular}{|l|c|c|c|}
\hline Severity of DR & \multicolumn{3}{|c|}{ Number of patients (\%) } \\
\hline Numerical ETDRS level & Baseline & 6 months & 12 months \\
\hline Mild non-proliferative (35) & 0 & 0 & $5(10.41)$ \\
\hline Moderate non-proliferative (47) & $24(50.00)$ & $29(60.41)$ & $33(68.75)$ \\
\hline Severe non-proliferative (53) & $10(20.83)$ & $12(25.00)$ & $5(10.41)$ \\
\hline Very severe non-proliferative (57) & $5(10.41)$ & $3(6.25)$ & $1(2.08)$ \\
\hline Non-high-risk proliferative (61) & $7(14.58)$ & $3(6.25)$ & $3(6.25)$ \\
\hline High-risk proliferative (71) & $2(4.16)$ & $1(2.08)$ & $1(2.08)$ \\
\hline
\end{tabular}

DR: diabetic retinopathy, ETDRS: early treatment diabetic retinopathy study.

Table 4. Binary logistic regression analysis on BCVA outcome at 12 months

\begin{tabular}{|l|c|c|c|}
\hline Variable & Loss of ETDRS letters & No loss of ETDRS letters & $p$ (Cl 95\%) \\
\hline Female gender, $\mathrm{n}(\%)$ & $6(31.6 \%)$ & $13(68.4 \%)$ & $0.29(1.3-2.34)$ \\
\hline Mean age, years \pm & $56.4 \pm 10$ & $62.5 \pm 6.7$ & $0.074(0.72-1.0)$ \\
\hline Mean duration of DM2, years \pm & $18.0 \pm 7.29$ & $16.5 \pm 4.95$ & $0.915(0.82-1.2)$ \\
\hline Mean baseline stage of DR, ETDRS scale & 50.1 & 50.7 & $0.91(0.82-1.23)$ \\
\hline Mean creatinine, $\mathrm{mg} / \mathrm{dl} \pm$ & $1.62 \pm 0.78$ & $1.25 \pm 0.61$ & $0.087(0.73-9.7)$ \\
\hline Mean baseline BCVA, ETDRS letters \pm & $21 \pm 15.6$ & $18 \pm 13.7$ & $0.536(0.91-1.1)$ \\
\hline Mean baseline HbA1c, \% \pm (mmol/mol) & $8.1 \pm 2.1(65)$ & $8.5 \pm 1.49(70)$ & $0.058(0.16-0.9)$ \\
\hline Mean baseline CRT, $\mu \mathrm{mm} \pm$ & $335 \pm 98$ & $364 \pm 99$ & $0.844(0.10-1.6)$ \\
\hline Mean number of injections & 10 & 6 & $0.562(0.23-4.5)$ \\
\hline
\end{tabular}

BCVA: best-corrected visual acuity, ETDRS: early treatment diabetic retinopathy study, CRT: central retinal thickness, DR: diabetic retinopathy, DM2: type 2 diabetes mellitus.

Table 5. Binary logistic regression analysis on BCVA improvement at 12 months

\begin{tabular}{|c|c|c|c|}
\hline Variable & $\begin{array}{l}\text { Mean BCVA change }>10 \\
\text { letters }\end{array}$ & $\begin{array}{c}\text { Mean BCVA change }<10 \\
\text { letters }\end{array}$ & P (Cl 95\%) \\
\hline Mean age, years \pm & $62.41 \pm 7.0$ & $62.7 \pm 7.0$ & $0.626(0.92-1.1)$ \\
\hline Male gender, $\mathrm{n}$ & 6 & 13 & $0.581(0.79-4.1)$ \\
\hline Mean duration of DM2, years \pm & $16.52 \pm 5.0$ & $16.55 \pm 5.0$ & $0.187(0.74-1.0)$ \\
\hline Mean baseline stage of DR, ETDRS scale \pm & $50.91 \pm 6.6$ & $50.51 \pm 9.24$ & $0.980(0.90-1.1)$ \\
\hline Mean baseline BCVA, ETDRS letters \pm & $18.2 \pm 13.16$ & $19.75 \pm 14.54$ & $0.75(0.87-1.1)$ \\
\hline Mean baseline $\mathrm{HbA} 1 \mathrm{c}, \% \pm(\mathrm{mmol} / \mathrm{mol})$ & $8.2 \pm 1.56(66)$ & $8.7 \pm 1.42(72)$ & $0.476(0.49-1.3)$ \\
\hline Mean creatinine, $\mathrm{mg} / \mathrm{dl} \pm$ & $1.0 \pm 0.48$ & $1.42 \pm 0.67$ & $0.057(0.420 .98)$ \\
\hline Mean baseline CRT, $\mu \mathrm{m} \pm$ & $340.52 \pm 61.81$ & $388.25 \pm 121.59$ & $0.102(0.97-1.39)$ \\
\hline Mean number of injections & 10.47 & 6.0 & $0.102(0.97-1.39)$ \\
\hline Total of eyes & 19 & 18 & \\
\hline
\end{tabular}

\pm Standard deviation. CRT: central retinal thickness, BCVA: best-corrected visual acuity. 
Table 6. Binary logistic regression analysis on CRT outcome at 12 months.

\begin{tabular}{|l|c|c|c|}
\hline Variable & CRT $<250 \mu m$ & CRT $>250 \mu m$ & $p$ (CI 95\%) \\
\hline Mean age, years \pm & $60.37 \pm 8.07$ & $64.30 \pm 7.00$ & $0.691(0.88-32.4)$ \\
\hline Mean duration of DM2, years \pm & $17.5 \pm 5.1$ & $14.9 \pm 5.8$ & $0.115(0.96-1.34)$ \\
\hline Mean baseline stage of DR, ETDRS scale \pm & $51.70 \pm 7.8$ & $47.61 \pm 7.8$ & $0.295(0.88-1.05)$ \\
\hline Mean creatinine, $\mathrm{mg} / \mathrm{dl} \pm$ & $1.38 \pm 0.10$ & $1.14 \pm 0.18$ & $0.848(0.86-1.18)$ \\
\hline Mean baseline BCVA, ETDRS letters \pm & $18.97 \pm 14.39$ & $19.07 \pm 13.26$ & $0.315(0.96-1.17)$ \\
\hline Mean HbA1c, $\% \pm(\mathrm{mmol} / \mathrm{mol})$ & $8.5 \pm 1.7(69)$ & $8.3 \pm 1.1(67)$ & $0.182(0.06-1.67)$ \\
\hline Mean baseline CRT, $\mu \mathrm{m} \pm$ & $336.88 \pm 66.46$ & $420.38 \pm 136.4$ & $0.032(1.00-1.03)$ \\
\hline Total of eyes & 35 & 13 &
\end{tabular}

\pm Standard deviation. BCVA: best-corrected visual acuity, ETDRS: early treatment diabetic retinopathy study, CRT: central retinal thickness, DR: diabetic retinopathy, DM2: type 2 diabetes mellitus.

Anti-VEGF agents have been found to be beneficial in proliferative $\mathrm{RD}^{14}$. In addition to visual improvement and anatomical outcomes in DME, in the present study, there were numerically fewer patients presenting severe non-proliferative and proliferative DR at 12 months compared to baseline. DRSS score significantly reduced from 50.59 to 45.79 ( $p<0.001$ ). Similarly, a post hoc analysis of the RISE and RIDE studies found that $56.8 \%$ of patients treated with ranibizumab experienced one-step or more improvement in DRSS from baseline to month $24,40 \%$ had no change, and $3.2 \%$ experienced DRSS worsening ${ }^{15}$. Furthermore, $17.1 \%$ of patients in the ranibizumab $0.5 \mathrm{mg}$ arm developed proliferative DR through 36 months compared to $39.1 \%$ of patients in the Sham group, which suggested that in eyes treated with ranibizumab, greater improvement in DRSS correlates with better clinical outcomes ${ }^{15}$.

In our study, treatment consisted of 3 monthly injections followed by PRN regimen as recommended by the clinical guidelines for the management of DME at ISSSTE ${ }^{13}$. Mean number of injections per treated eye was 6.7 over 12 months. This is consistent with the number of injections reported by the RETAIN study, in which patients in the ranibizumab PRN arm received a mean of seven injections in 12 months $^{8}$. In the RESTORE extension study, patients received a declining number of injections per year, namely, 7.9 the $1^{\text {st }}$ year, 3.9 the second, and 2.9 in the third $^{7}$. Therefore, this treatment regimen has the potential to reduce treatment burden in health-care institutions.
A large epidemiological study conducted in the ophthalmology service of General Hospital of Mexico ( $n=13,670$ ) found that $71 \%$ of diabetic patients had any type of DR, of which $63 \%$ had the non-proliferative variant and $37 \%$ proliferative DR, with $16 \%$ of patients presenting DME at any stage of $\mathrm{DR}^{3}$. In contrast, the prevalence of DR in a large cohort of diabetic patients $(n=$ 369,047 ) in the United Kingdom was 43\%, of which $11 \%$ had proliferative $\mathrm{DR}^{16}$. This suggests that the prevalence of DR and proliferative DR is higher in the Mexican population, possibly due to genetic and lifestyle factors as well as substantial differences in the detection and management of DM2 and DR between both countries. Most randomized clinical trials in DME were conducted in developed countries; therefore, it is important to consider whether population variability exerts an effect on clinical outcomes in DME. Although this question remains outside the scope of this study, we explored whether baseline characteristics of our patient sample affected treatment outcomes at month 12 .

The logistic regression analysis found a significant association between baseline CRT and persistent macular thickness at month 12 . Hence, it might be reasonable to consider baseline CRT in determining the optimal monitoring and retreatment frequency in each patient. On the other hand, baseline BCVA has been found to be a predictive factor for final BCVA ${ }^{17}$. In the present study, nevertheless, we found no association between initial and final VA.

Limitations of the study include sample size. Further studies with larger samples are necessary to determine predicting factors of BCVA and CRT outcomes. 


\section{Conclusion}

In this study, patients experienced visual and anatomical improvement after receiving ranibizumab injections in a real-world setting. We observed that monthly monitoring and individualized retreatment based on visual and anatomic criteria result in clinical outcomes potentially similar to those reported in large multicentric trials. Adherence to PRN regimen might also be useful in reducing treatment burden within public health-care institutions in Mexico. Further studies are necessary to determine effectiveness in a broader population, improvement in vision-related quality of life, and cost-effectiveness of ranibizumab in Mexican health-care institutions.

\section{Conflicts of interest}

The authors declare there are no conflicts of interest in conducting and publishing this study.

\section{Funding sources}

This research did not receive any specific grant from funding agencies in the public, commercial, or not-forprofit sectors.

\section{Ethical disclosures}

Protection of human and animal subjects. The authors declare that the procedures followed were in accordance with the regulations of the relevant clinical research ethics committee and with those of the code of ethics of the World Medical Association (Declaration of Helsinki).

Confidentiality of data. The authors declare that they have followed the protocols of their work center on the publication of patient data.

Right to privacy and informed consent. The authors have obtained the written informed consent of the patients or subjects mentioned in the article. The corresponding author is in possession of this document.

\section{References}

1. International Diabetes Federation. IDF Diabetes Atlas. $7^{\text {th }}$ ed. Brussels, Belgium: IDF Executive Office; 2015. Available from: http://www.diabetesatlas.org.[Last accessed on 2017 Mar 20].

2. Hernandez-Avila M, Gutierrez JP. Diabetes Mellitus: la Urgencia de Reforzar la Respuesta en Políticas Públicas Para su Prevención y Control. Mexico: Instituto Nacional de Salud Pública; 2012.

3. Prado-Serrano A, Guido-Jimenez MA, Camas-Benitez JT. Prevalencia de retinopatía diabética en población mexicana. Rev Mex Oftalmol. 2009;83:261-6.

4. Klein R, Klein BE, Moss SE, Davis MD, DeMets DL. The Wisconsin epidemiologic study of diabetic retinopathy. IV. Diabetic macular edema. Ophthalmology. 1984;91:1464-74.

5. Boyer DS, Hopkins JJ, Sorof J, Ehrlich JS. Anti-vascular endothelial growth factor therapy for diabetic macular edema. Ther Adv Endocrinol Metab. 2013;4:151-69.

6. Massin P, Bandello F, Garweg JG, Hansen LL, Harding SP, Larsen M, et al. Safety and efficacy of ranibizumab in diabetic macular edema (RESOLVE study): a 12-month, randomized, controlled, double-masked, multicenter phase II study. Diabetes Care. 2010;33:2399-405.

7. Mitchell $P$, Massin P, Bressler S, Coon CD, Petrillo J, Ferreira A, et al. Three-year patient-reported visual function outcomes in diabetic macular edema managed with ranibizumab: the RESTORE extension study. Curr Med Res Opin. 2015;31:1967-75.

8. Prünte C, Fajnkuchen F, Mahmood S, Ricci F, Hatz K, Studnička J, et al. Ranibizumab $0.5 \mathrm{mg}$ treat-and-extend regimen for diabetic macular oedema: the RETAIN study. Br J Ophthalmol. 2016;100:787-95.

9. Sherman RE, Anderson SA, Dal Pan GJ, Gray GW, Gross T, Hunter NL, et al. Real-world evidence what is it and what can it tell us? N Engl J Med. 2016;375:2293-7.

10. Bertelmann T, Feltgen N, Scheffler M, Hufenbach $U$, Wiedon A, Wilhelm $\mathrm{H}$, et al. Vision-related quality of life in patients receiving intravitreal ranibizumab injections in routine clinical practice: baseline data from the german OCEAN study. Health Qual Life Outcomes. 2016;14:132.

11. Ghanchi $F$, Hazel CA. South Asian diabetic macular oedema treated with ranibizumab (ADMOR)-real-life experience. Eye (Lond). 2016;30:133-8.

12. Granström $\mathrm{T}$, Forsman $\mathrm{H}$, Olinder AL, Gkretsis D, Eriksson JW, Granstam E, et al. Patient-reported outcomes and visual acuity after 12 months of anti-VEGF-treatment for sight-threatening diabetic macular edema in a real world setting. Diabetes Res Clin Pract. 2016;121:157-65.

13. Hernández-Salazar L, Aranda-Serna S, Orozco-Gómez LP, Azuara-Azuara C, Bracamontes-Barragán J, Collado-Solórzano A, et al. Guía para el diagnóstico y el tratamiento del edema macular diabético en derechohabientes del ISSSTE. Rev Espec Med Quir. 2015;20:321-7.

14. Osaadon $P$, Fagan XJ, Lifshitz $T$, Levy J. A review of anti-VEGF agents for proliferative diabetic retinopathy. Eye (Lond). 2014;28:510-20.

15. Ip MS, Zhang J, Ehrlich JS. The clinical importance of changes in diabetic retinopathy severity score. Ophthalmology. 2017;124:596-603.

16. Mathur R, Bhaskaran K, Edwards E, Lee H, Chaturvedi N, Smeeth L, et al. Population trends in the 10-year incidence and prevalence of diabetic retinopathy in the UK: a cohort study in the clinical practice research data link 2004-2014. BMJ Open. 2017;7:e014444.

17. Dugel PU, Hillenkamp J, Sivaprasad S, Vögeler J, Mousseau MC, Wenzel A, et al. Baseline visual acuity strongly predicts visual acuity gain in patients with diabetic macular edema following anti-vascular endothelial growth factor treatment across trials. Clin Ophthalmol. 2016;10:1103-10. 